Check for updates

Cite this: RSC Adv., 2019, 9, 4463

\title{
A fluorescent biosensor for cardiac biomarker myoglobin detection based on carbon dots and deoxyribonuclease I-aided target recycling signal amplification $\uparrow$
}

\author{
Jishun Chen, ${ }^{\mathrm{ab}}$ Fengying Ran, ${ }^{\mathrm{b}}$ Qinhua Chen, (D) ${ }^{\mathrm{bc}}$ Dan Luo, ${ }^{\mathrm{b}}$ Weidong Ma, ${ }^{\mathrm{a}}$ Tuo Han, ${ }^{\mathrm{a}}$ \\ Ceming Wang ${ }^{\mathrm{b}}$ and Congxia Wang (D) *a
}

\begin{abstract}
A sensitive biosensor using carbon dots and deoxyribonuclease I-aided target recycling signal amplification has been developed to detect myoglobin (MB), which is an important cardiac biomarker and plays a major role in the diagnosis of acute myocardial infarction (AMI). Here, in the absence of MB, the MB aptamer (Ap) is absorbed on the surface of carbon dots (CDs) through $\pi-\pi$ stacking interactions, resulting in quenching of the fluorescent label by forming $C D$-aptamer complexes. Upon adding MB, the Ap sequences could be specifically recognized by $M B$, leading to the recovery of quenched fluorescence. Thus, quantitative evaluation of $M B$ concentration has been achieved in a broad range from $50 \mathrm{pg} \mathrm{mL}^{-1}$ to $100 \mathrm{ng} \mathrm{mL}^{-1}$, and the detection limit is as low as $20 \mathrm{pg} \mathrm{mL}^{-1}$. This strategy is capable of specific and sensitive detection of MB in human serum, urine, and saliva and can be used for the diagnosis of $A M I$ in the future.
\end{abstract}

Received 16th November 2018 Accepted 20th January 2019

DOI: $10.1039 / \mathrm{c} 8 \mathrm{ra09459d}$

rsc.li/rsc-advances surface-enhanced Raman spectroscopy, ${ }^{15}$ single polyaniline nanowire biosensor, ${ }^{16}$ electrosynthesis of molecularly imprinted polymer, ${ }^{17}$ and fluorescence. ${ }^{18}$ Among the reported methods, fluorescence-based methods have attracted special attention due to their high sensitivity, specificity, easy readout and simple instruments. ${ }^{\mathbf{1 9}, 20}$ Despite many advances in this field, however, fluorescence methods suffer from several limitations including the highcost material, fluorescence labeling and the use of traditional low light stability fluorescent dyes. Thus, it is still urgent and significant to develop a simple and sensitive method for MB detection.

Aptamers, as an artificial DNA or RNA molecules (approximately 12-80 nucleotides), can bind to cells, proteins and small molecules with high specificity, selectivity, and sensitivity. ${ }^{\mathbf{2 1 , 2 2}}$ Compared with antibodies and enzymes, aptamers show one important advantage is that more stable and high resistance in the environment, easy artificial synthesis and easy storage. ${ }^{23,24}$ Moreover, aptamers can show high specificity and affinity for their targets, due to their structural flexibility and easily bear labels allows for adaptability of significant conformational changes after specific binding of aptamers to targets. ${ }^{25}$ Thus, aptamers have been widely used in the biometrics of proteins, cancer cells, and tumor medicine. ${ }^{26}$

Nowadays, several fluorescent nanomaterials have been employed to provide fluorescence response, such as organic dyes, quantum dots (QDs) and noble metal nanoclusters (NCs) have been reported of biosensing. ${ }^{27}$ However, there are some disadvantages including poor photostability, low solubility in water and narrow excitation spectra. It is necessary to search for better fluorophores in biological applications. The fluorescent carbon
${ }^{a}$ Department of Cardiology, The Second Affiliated Hospital of Xi'an Jiaotong University, Xi'an, Shanxi, 710004, China. E-mail:wcx622@163.com; Tel: +86-02987679770

${ }^{b}$ Affiliated Dongfeng Hospital, Hubei University of Medicine, Shiyan, Hubei, 442008, China

${ }^{c}$ Shennongjia Golden Monkey Key Laboratory of Conservation Biology in Hubei Province, Shennongjia, Hubei 442400, China

$\dagger$ Electronic supplementary information (ESI) available. See DOI: 10.1039/c8ra09459d 
dots (CDs), as a new class of carbon-based nonmaterial's that quasispherical nanoparticles less than $10 \mathrm{~nm}$ in size, ${ }^{28}$ ease of synthesis, superior water dispersibility and stable fluorescence intensity. ${ }^{29}$ Consequently, CDs are attracted numerous attentions, and make its promising candidates for biosensor and clinical diagnostics. ${ }^{30-32}$ Meanwhile, because of the ratio of the aptamer to target is $1: 1$ in almost all technologies, thus their ordinarily show low sensitivity and a high error rate. To overcome these limitations, the enzyme-aided signal amplification, including DNAzymes, exonucleases, nicking endonucleases, deoxyribonuclease I (DNase I), etc., have recently been developed to achieve the sensitive detection of biomolecules. ${ }^{33-35}$ Among these enzyme-aided signal amplification, DNase I has the advantages of being highly sensitive, easy to use and inexpensive, reliable and specific. ${ }^{36}$ Moreover, DNase I can cleave phosphodiester bonds to product many polynucleotides with $5^{\prime}$-phosphate and $3^{\prime}-\mathrm{OH}$ groups, but cannot digest RNA sequences. ${ }^{37,38}$ Thus, these make it suitable for MB detection based on DNase Iassisted target recycling and signal amplification.

Hence, we report a sensitive and rapid aptasensing platform for the detection of MB based on the carbon dots and DNase Iaided target recycling signal amplification. In this work, upon addition of $\mathrm{MB}$, the $\mathrm{MB}$ aptamer can recognize $\mathrm{MB}$ specifically and result in aptamer being away from CDs, then, while the DNase I is introduced, the DNase I target recycling signal amplification strategy, lead to cyclic reuse of the MB and quantities of $\mathrm{MB}$ can be achieved by fluorescence increment, was the $\mathrm{MB}$ concentration linear range from $50 \mathrm{pg} \mathrm{mL}^{-1}$ to $100 \mathrm{ng} \mathrm{mL}^{-1}$,

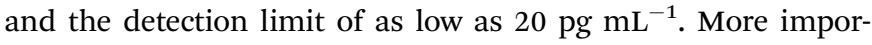
tantly, the sensor has been successfully applied to the detection of MB in various spiked biological samples, thus, this study not only provides a reliable method for the sensitive detection of $\mathrm{MB}$, but also indicates that CDs and DNase I have becoming a promising star in the application of clinical diseases diagnosis.

\section{Experimental section}

\subsection{Reagents and materials}

The deoxyribonuclease I (DNase I) were obtained from solarbio (Beijing, China, http://www.solarbio.com). The MB, CD63, BSA, EPCAM and VEGF were purchased from Cusabio Biotech Co. Ltd. (http://www.cusabio.cn/). The MB aptamer (5'CCCTCCTTTCCTTCGACGTAGATCTGCTGCGTTGTTCCGA-3' -

FAM) were synthesized by Sangon Biological Engineering Technology Co., Ltd. (Shanghai, China, http:// www.sangon.com) and purified using high performance liquid chromatography. All reagents employed were of analytical grade and used without further purification. And were diluted to the required concentration with working buffer $(10 \mathrm{mM}$ Tris, $100 \mathrm{mM} \mathrm{NaNO}$, pH 7.4) before usage. This study all experiments were performed in compliance with the relevant laws and institutional guidelines (National Health Commission of the people's Republic of china, ethical review of biomedical research involving human beings), healthy human serum, urine and saliva were provided by Affiliated Dongfeng Hospital, Hubei University of Medicine, and approved by Dongfeng Hospital's Ethics Committee, informed consent was obtained for any experimentation with human subjects. Ultrapure water obtained from a Millipore water purification system $(18.2 \mathrm{M} \Omega \mathrm{cm}$ resistivity, Milli-Q Direct 8) was used in all runs.

\subsection{Synthesis of CDs}

The CDs were synthesized by an electro-chemical method. In a typical procedure, Firstly, two graphite rods (diameter 6.15 $\mathrm{mm}$, length $15 \mathrm{~cm}$ ) were placed into ultrapure water. Then, a bias of $30 \mathrm{eV}$ was applied to the two electrodes and constant stirring for $120 \mathrm{~h}$. Afterward, the dark yellow solution was formed. After that, the resultant solution was filtered for three times and formed the CDs solution. Lastly, the CDs solution though treated in a freeze-drying way and acquired the CDs powder.

\subsection{Apparatus and measurements}

Firstly, the 30 nM FAM labeled MB aptamer (Ap) and a desired concentration of $\mathrm{MB}$ was first mixed and kept at $37{ }^{\circ} \mathrm{C}$ for $20 \mathrm{~min}$, followed by adding $20 \mu \mathrm{g} \mathrm{mL}^{-1}$ of CDs. 5 min later, the reaction solution was added with $6 \mathrm{U} \mathrm{mL}^{-1}$ DNase I and incubated at $37{ }^{\circ} \mathrm{C}$ for $30 \mathrm{~min}$. Finally, the fluorescence of the mixture was carried out on a Hitachi F-4600 spectrophotometer (Hitachi Co. Ltd, Japan) equipped with a xenon lamp excitation source at room temperature. The excitation was set at $495 \mathrm{~nm}$ and the emission spectra were collected from $510 \mathrm{~nm}$ to $600 \mathrm{~nm}$. The fluorescence intensity at $517.6 \mathrm{~nm}$ was used to choose the optimal experimental conditions and evaluate the performance of the proposed sensing system. In control experiments, the measurement process was all the same with the above except the addition of MB. Unless otherwise noted, each fluorescence measurement was repeated three times, and the standard deviation was plotted as the error bar.

\section{Results and discussion}

\subsection{Characterization of CDs and principle of design}

Fig. 1 shows the TEM image of the CDs, it is consistent with the publicly reported CDs structure. ${ }^{39}$ And the more characterizations of as-synthesized CDs are shown in ESI. $\uparrow$ In the present study, the principle of fluorescent biosensor detection of $\mathrm{MB}$ based on carbon dots and DNase I-aided target recycling signal amplification is illustrated in Fig. 2. According to the literature report, the as prepared C-dots are predominantly multi-layer graphene oxide, therefore, C-dots has similar characteristics to GO, the ability to adsorb single-stranded DNA by $\pi-\pi$ stacking interactions is weaker than that of small fragment DNA. $^{40-42}$ Thus, in the absence of MB, the CDs enabled strong adsorption of Ap to the surface of CDs, leading to the effective fluorescence quenching. Upon the addition of $\mathrm{MB}$, the stronger binding affinity between $\mathrm{MB}$ and their corresponding aptamers induced unwinding of MB-aptamer from the CDs surface, resulting in the recovery of quenched fluorescence. Then, when the DNase I is added, all DNA sequences are degraded, leading to the release of MB and FAM fluorophores. The released MB is recycled repeatedly, resulting in the accumulation of free FAM fluorophores. Thus, the fluorescence signal is significantly 


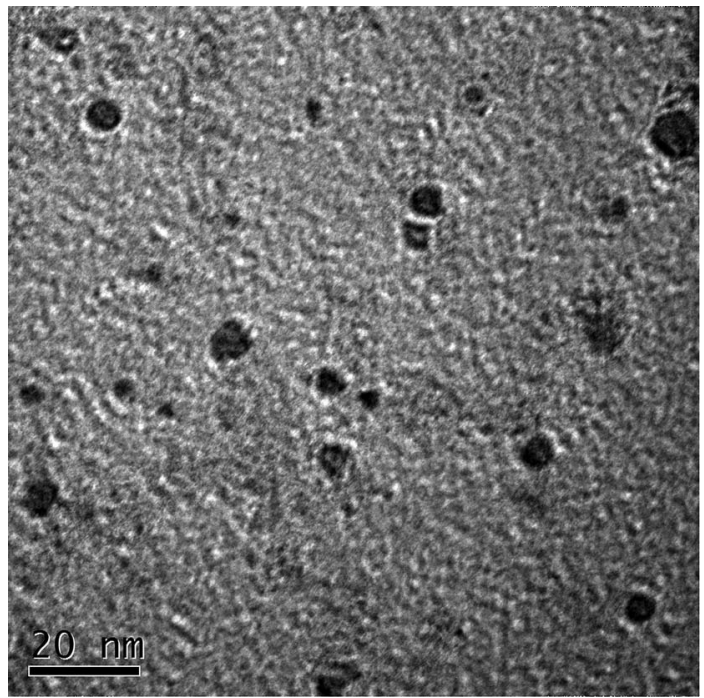

Fig. 1 The TEM image of CDs.

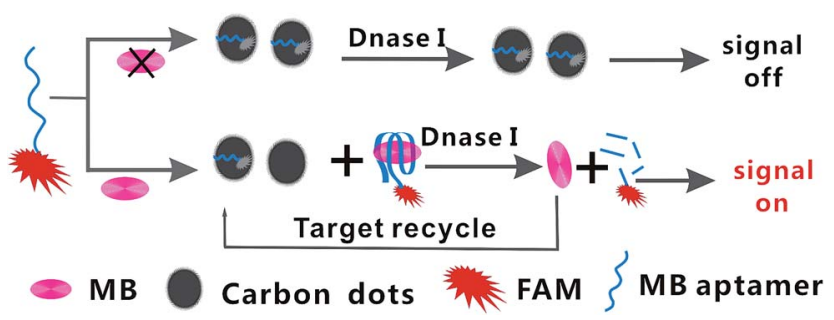

Fig. 2 Schematic illustration of the fluorescent biosensor assay detection of MB by using carbon dots and DNase I-mediated target cyclic amplification.

amplified by DNase I-mediated target recycling process, and the quantities of MB can be achieved by fluorescence increment.

\subsection{Feasibility analysis of the developed method for $\mathrm{MB}$ detection}

To further verify the feasibility of the proposed mechanism. Fig. 3 shows the fluorescence emission spectra of the Ap under different conditions. The fluorescence of the $30 \mathrm{nM}$ Ap alone displayed a strong fluorescence emission, which acted as the control experiment (curve a). The introduction of CDs-aptamer complexes quenched the fluorescence emission (curve d), resulting in an intensity decreased remarkably that of the control experiment. It is suggested that CDs can interact with the Ap and absorb it. When DNase I was added to a solution of $30 \mathrm{nM}$ Ap and $20 \mu \mathrm{g} \mathrm{mL} \mathrm{m}^{-1} \mathrm{CDs}$, the fluorescence intensity do not obviously increase (curve c), indicating the Ap cannot specifically bind to $\mathrm{MB}$, lead to the FAM fluorophores are produced. However, upon adding MB, significant enhancement of the fluorescence intensity was observed (curve b), as a result of the stronger binding affinity between $\mathrm{MB}$ and their corresponding aptamers induced unwinding of MB-aptamer from the CDs surface. More importantly, the DNase I-aided target recycling results in the significant fluorescence amplification. These results suggested that CDs and DNase I can be used as a sensing platform for MB.

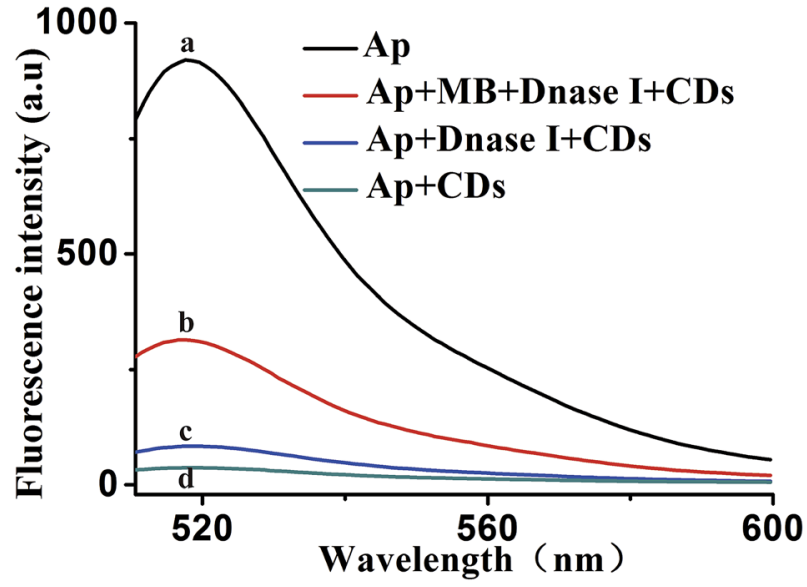

Fig. 3 The feasibility analysis. (a) Ap; (b) Ap + MB + DNase I + CDs; (c) Ap + DNase I + CDs. (d) Ap + CDs. The concentrations of Ap, MB, DNase I and $C D s$ were $30 \mathrm{~nm}, 5 \mathrm{ng} \mathrm{mL}^{-1}, 6 \mathrm{U} \mathrm{mL}^{-1}$ and $20 \mu \mathrm{g} \mathrm{mL}^{-1}$, respectively.

\subsection{Optimization of reaction conditions}

To achieve optimal sensing performance, several reaction conditions such as the concentration of DNase I, the concentration of CDs, the enzyme digestion time and reaction temperature were optimized. The $F_{1}$ and $F_{0}$ were the fluorescence intensities in the presence and absence of $\mathrm{MB}$, respectively. The fluorescence intensity and the value of $F_{1} / F_{0}$ are selected to evaluate the effects of the reaction conditions on the sensing performance of the assay. Fig. $4 \mathrm{~A}$ illustrates how the fluorescence change is related to the concentration of CDs after the isothermal amplification; the highest $F_{1} / F_{0}$ ratio for this work was detected when the concentration of CDs was $20 \mu \mathrm{g}$ $\mathrm{mL}^{-1}$. Thus, $20 \mu \mathrm{g} \mathrm{mL} \mathrm{m}^{-1}$ CDs was employed for analytical purpose in this method. The concentration of DNase I plays an important role in this sensor. In order to obtain high sensitivity, the concentration of DNase I should be optimized. As depicted in Fig. 4B, with the increase in the concentration of DNase I, the fluorescence intensity initially increased and then gradually decrease, and maximum $F_{1} / F_{0}$ values are observed when the concentration of DNase $\mathrm{I}$ is $6 \mathrm{U} \mathrm{mL}^{-1}$. Thus, $6 \mathrm{U} \mathrm{mL}^{-1}$ DNase I was selected for the rest of the experiments.

In addition, other experimental conditions, such as the enzyme digestion time and reaction temperature can also affect the detection sensitivity. A series of experiments were carried out to optimize the sensitivity of this sensor. As shown in Fig. 5A, maximum $F_{1} / F_{0}$ values are observed when enzyme digestion time is $30 \mathrm{~min}$. Thus, $30 \mathrm{~min}$ of enzyme digestion time was used in the subsequent experiments. The effect of the enzyme reaction temperature has also been investigated. As shown in Fig. 5B, the maximum $F_{1} / F_{0}$ signal was obtained at $37{ }^{\circ} \mathrm{C}$. Therefore, an enzyme reaction temperature of $37^{\circ} \mathrm{C}$ was selected in this work.

\subsection{Sensitivity and specificity}

Under the optimal reaction conditions, the sensitivity of the sensor for detection of MB is investigated. Fig. 6A shows the fluorescence emission spectra of the biosensor incubated in different concentrations of $\mathrm{MB}\left(0,100 \mathrm{pg} \mathrm{mL}^{-1}, 500 \mathrm{pg} \mathrm{mL}^{-1}, 1\right.$ 
A

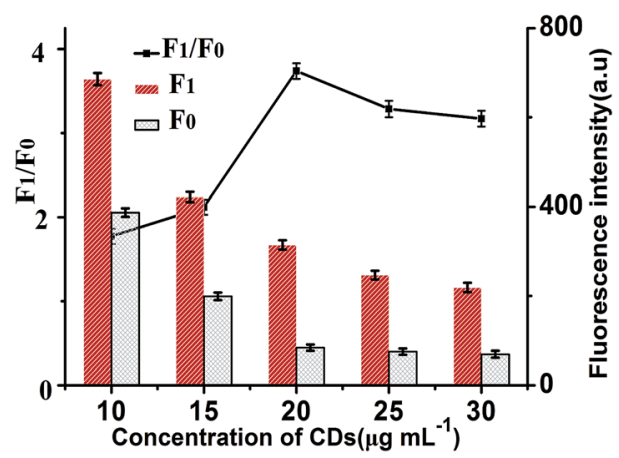

B

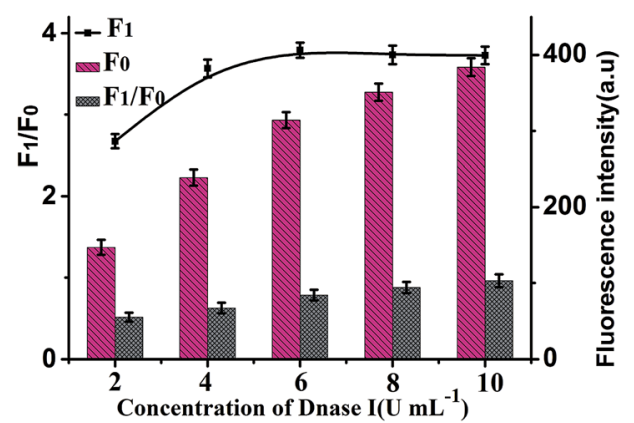

Fig. 4 (A) The effect of CDs concentration on the fluorescence response of this method. (B) The effect of DNase I concentration on the fluorescence response of this method. $F_{0}$ : in the absence of $M B ; F_{1}$ : in the present of $M B$, and the concentrations of $A p$ and $M B$ were $30 \mathrm{~nm}$ and 5 $\mathrm{ng} \mathrm{mL} \mathrm{m}^{-1}$. The black lines represent the $F_{1} / F_{0}$ at different conditions, while the $F_{1}$ and $F_{0}$ were the fluorescence intensities in the presence and absence of $M B$, respectively. Error bars: $S D, n=3$.

A

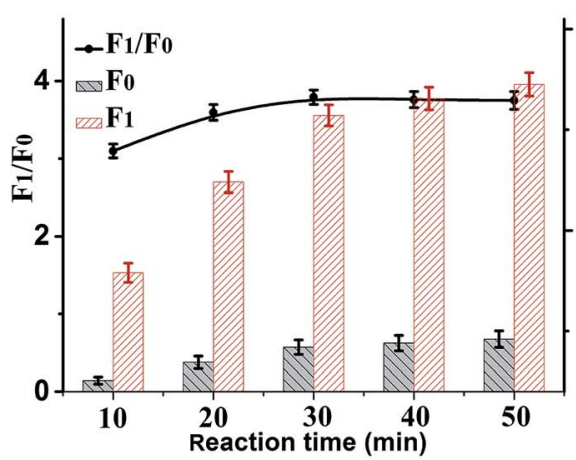

B

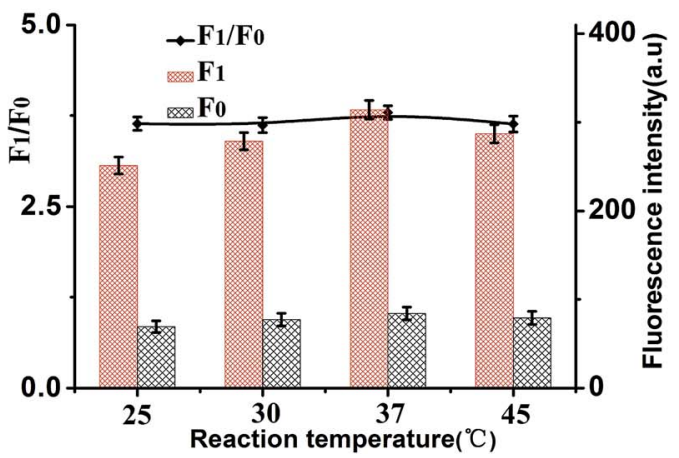

Fig. 5 The effect of enzyme digestion reaction time and reaction temperature on the fluorescence intensity at the emission wavelength of $517.6 \mathrm{~nm}$. The concentrations of Ap, MB, DNase I and CDs were $30 \mathrm{~nm}, 5 \mathrm{ng} \mathrm{mL}^{-1}, 6 \mathrm{U} \mathrm{mL}^{-1}$ and $20 \mu \mathrm{gL}^{-1}$, respectively. Error bars: SD, $n=3$.

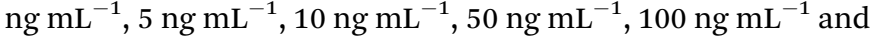
$200 \mathrm{ng} \mathrm{mL} \mathrm{mL}^{-1}$ ). We found that the fluorescence intensity decreased proportionally with the amount of MB introduced. It illustrates a strong concentration dependence of the sensor for detection of MB. At the same time, Fig. 6B shows a good linear correlation between the fluorescence intensity and the
A

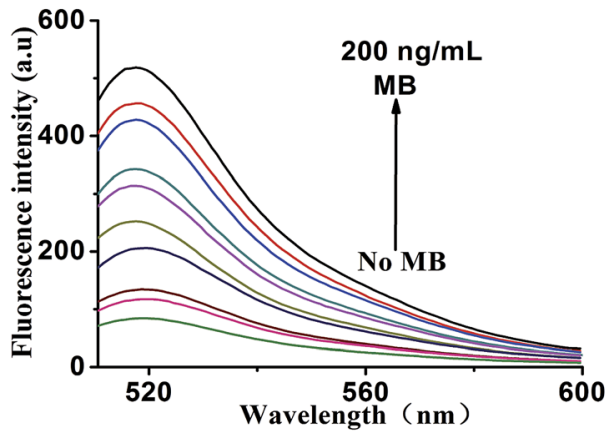

B

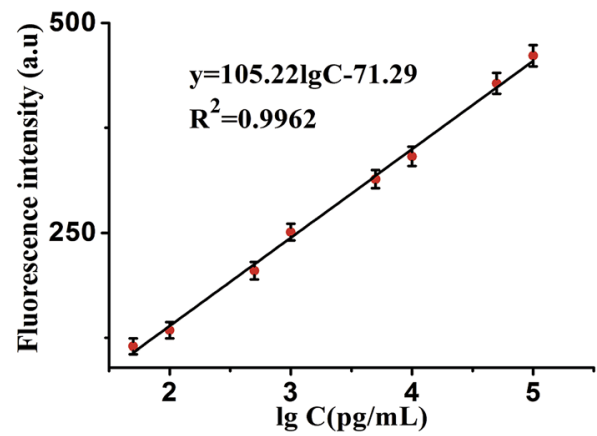

Fig. 6 (A) Fluorescence emission spectra of the biosensor in the presence of MB with different concentrations: from bottom to top: 0,100 pg $\mathrm{mL}^{-1}, 500 \mathrm{pg} \mathrm{mL}^{-1}, 1 \mathrm{ng} \mathrm{mL}^{-1}, 5 \mathrm{ng} \mathrm{mL}^{-1}, 10 \mathrm{ng} \mathrm{mL}^{-1}, 50 \mathrm{ng} \mathrm{mL}^{-1}, 100 \mathrm{ng} \mathrm{mL}^{-1}$ and $200 \mathrm{ng} \mathrm{mL}^{-1}$, respectively. (B) The relationship curve of the fluorescence intensity as a function of $M B$ concentration. While shows the relationship between fluorescence intensity and $M B$ concentration, both experimental conditions: Ap, MB, DNase I and CDs were $30 \mathrm{~nm}, 5 \mathrm{ng} \mathrm{mL}-1,6 \mathrm{U} \mathrm{mL} \mathrm{L}^{-1}$ and $20 \mu \mathrm{g} \mathrm{mL} \mathrm{m}^{-1}$, respectively, and the emission wavelength of $517.6 \mathrm{~nm}$. Error bars: SD, $n=3$. 
Table 1 The comparison of designed method with other reported biosensors

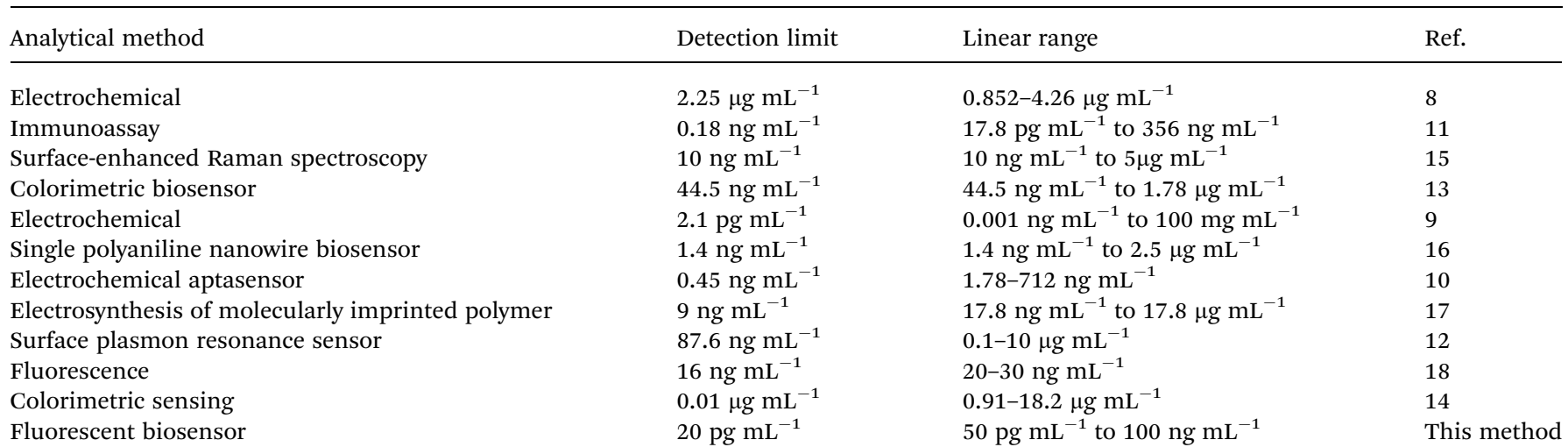

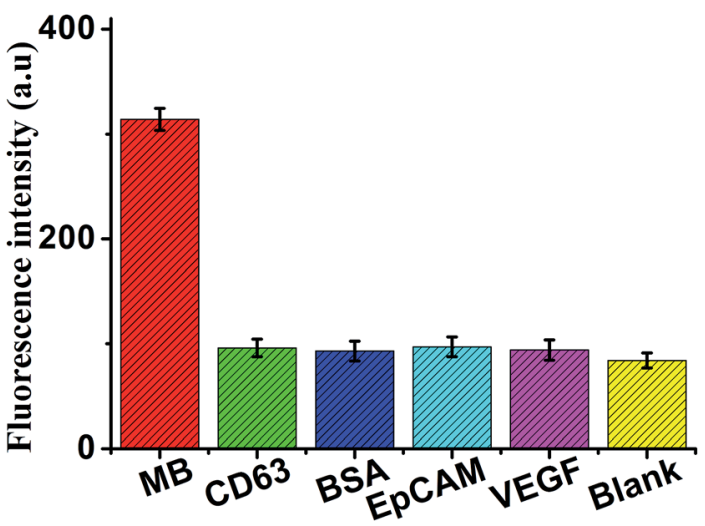

Fig. 7 Fluorescence intensity (at the emission wavelength of 517.6 $\mathrm{nm}$ ) of the sensor in the presence of MB $\left(5 \mathrm{ng} \mathrm{mL}^{-1}\right), \mathrm{CD} 63(50 \mathrm{ng}$ $\left.\mathrm{mL}^{-1}\right), \mathrm{BSA}\left(50 \mathrm{ng} \mathrm{mL}^{-1}\right), \operatorname{EPCAM}\left(50 \mathrm{ng} \mathrm{mL}^{-1}\right), \operatorname{VEGF}\left(50 \mathrm{ng} \mathrm{mL}^{-1}\right)$ and black, respectively. Error bars: SD, $n=3$.

concentration of $\mathrm{MB}$ in the range from $50 \mathrm{pg} \mathrm{mL}^{-1}$ to $100 \mathrm{ng}$ $\mathrm{mL}^{-1}$. The calibration plot of the linear equation is given as $y=$ 105.22 $\lg c-71.29\left(R^{2}=0.9962\right)$, where $\lg c$ is the logarithm of MB concentration and $y$ is the fluorescence intensity. Further-

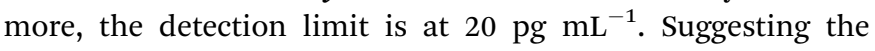
sensitivity of this analytical strategy. As far as we know, the

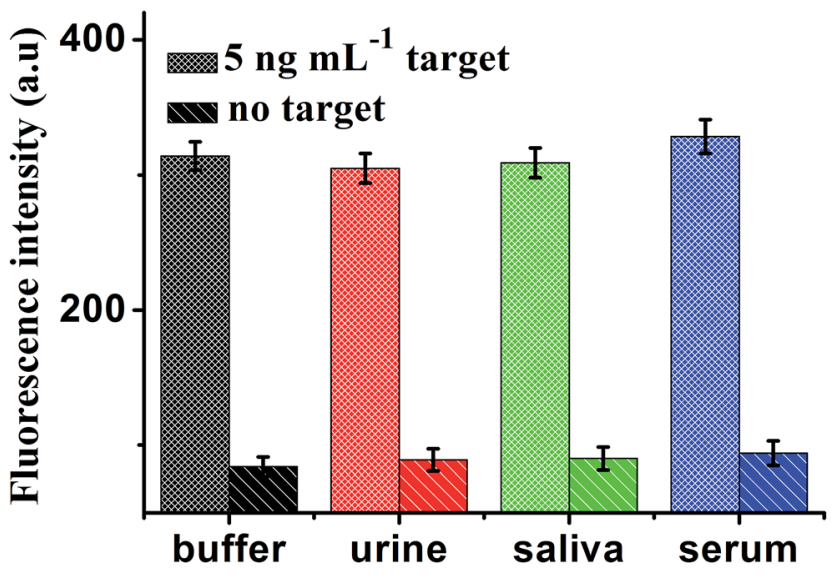

Fig. 8 Fluorescence intensity of the sensor for detection of MB in buffer and blank biological samples (human urine, saliva and serum, respectively). Error bars: SD, $n=3$. linear range and the detection limit here we showed was obviously superior compared with those of previous reports Table 1 demonstrating that the approach we proposed may match the higher requirement for assaying MB.

In addition, for the specificity study, adding different control proteins was investigated, including CD63, BSA, EpCAM, and

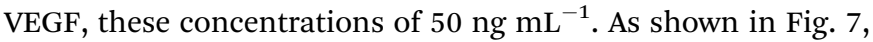
in the presence of other control proteins, the significant increase of fluorescence signal is observed in the presence of the $\mathrm{MB}\left(5 \mathrm{ng} \mathrm{mL}^{-1}\right)$, indicating that this proposed strategy exhibited good specificity for MB detection.

\subsection{Analysis of MB in real samples}

To further verify the potential applicability of this present strategy in biological samples, the detection of $\mathrm{MB}$ in biological samples by spiking MB to human urine, saliva and serum diluted to $10 \%$ with a buffer solution with the final concentration of $5 \mathrm{ng} \mathrm{mL}{ }^{-1}$ were performed. As shown in Fig. 8, a significant increase in various biological samples is observed, compared with no spiking biological samples. These results clearly demonstrate that this sensor can be a potential analytical method to detect MB in real samples sensitively.

\section{Conclusions}

In summary, a specific and sensitive strategy for assaying $\mathrm{MB}$ using carbon dots and DNase I-aided target recycling signal amplification sensing platform was proposed. The fluorescence of the FAM-labeled MB aptamer was quenched efficiently by CDs in the absence of the target MB. Upon the addition of MB, the Ap and MB formed complexes that remained away from the CDs surface, and thereby preserved the fluorescence of FAM. As to $\mathrm{MB}$, this sensor can detect $\mathrm{MB}$ with a linear range from $50 \mathrm{pg} \mathrm{mL}^{-1}$ to $100 \mathrm{ng} \mathrm{mL}^{-1}$, and the detection limit was low to

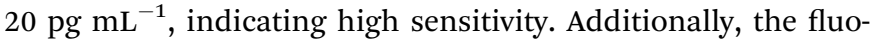
rescence signals are also obtained when this sensor is used for biological samples. Aptamer can recognize MB specifically, and thus provide a promising method for its assay, this promising strategy might prove feasible as an MB assay for real samples. We believe that the present work will demonstrate its potentials for practical applications in cardiac disease diagnostics. 


\section{Conflicts of interest}

There are no conflicts to declare.

\section{Acknowledgements}

These works were supported by the National Natural Science Foundation of China (81872509), Open Project Fund of Shennongjia Golden Monkey Conservation Biology Hubei Provincial Key Laboratory (201801), Hubei Provincial Technology Innovation Project (2017ACA176), Hubei University of Medicine Free exploration Project (FDFR201804), the Natural Science Foundation of Hubei Provincial Department of Education (No. B2016140), the Science and Technology Key Program of Shiyan (No. 18Y81 and 18Y82) and Hubei Province Health and Family Planning Scientific Research Project (WJ2019M054).

\section{References}

1 A. L. Straface, J. H. Myers, H. J. Kirchick and K. E. Blick, Am. J. Clin. Pathol., 2008, 129, 788-795.

2 J. S. Alpert, K. Thygesen, E. Antman and J. P. Bassand, J. Am. Coll. Cardiol., 2000, 36, 959-969.

3 J. Mccord, M. P. Nowak RMHudson, P. A. Mccullough, M. C. Tomlanovich, G. Jacobsen, G. Tokarski, N. Khoury and W. D. Weaver, Ann. Emerg. Med., 2003, 42, 343-350.

4 A. Qureshi, Y. Gurbuz and J. H. Niazi, Sens. Actuators, B, 2012, 171-172, 62-76.

5 B. A. Wittenberg and J. B. Wittenberg, Annu. Rev. Physiol., 1989, 51, 857-878.

6 T. Naka, D. Jones, I. Baldwin, N. Fealy, S. Bates, H. Goehl, S. Morgera, H. H. Neumayer and R. Bellomo, Critical Care, 2005, 9, R90-R95.

7 R. H. Christenson and H. M. E. Azzazy, Clin. Biochem., 2009, 42, 150-157.

8 F. T. C. Moreira, R. A. F. Dutra, J. P. C. Noronha and M. G. F. Sales, Electrochim. Acta, 2013, 107, 481-487.

9 J. A. Ribeiro, C. M. Pereira, A. F. Silva and S. Mgf, Anal. Chim. Acta, 2017, 981, 41-52.

10 S. M. Taghdisi, N. M. Danesh, M. Ramezani, A. S. Emrani and K. Abnous, Biosens. Bioelectron., 2016, 80, 532-537.

11 O. V. Gnedenko, Y. V. Mezentsev, A. A. Molnar, A. V. Lisitsa, A. S. Ivanov and A. I. Archakov, Anal. Chim. Acta, 2013, 759, 105-109.

12 B. Osman, L. Uzun, N. Besirli and A. Denizli, Mater. Sci. Eng., C, 2013, 33, 3609-3614.

13 Q. Wang, X. Yang, X. Yang, F. Liu and K. Wang, Sens. Actuators, B, 2015, 212, 440-445.

14 X. Zhang, X. Kong, W. Fan and X. Du, Langmuir, 2011, 27, 6504-6510.

15 W. A. El-Said, D. M. Fouad and S. A. El-Safty, Sens. Actuators, $B, 2016,228,401-409$.

16 I. Lee, X. Luo, X. T. Cui and M. Yun, Biosens. Bioelectron., 2011, 26, 3297-3302.
17 V. V. Shumyantseva, T. V. Bulko, L. V. Sigolaeva, A. V. Kuzikov, M. A. Shatskaya and A. I. Archakov, Dokl. Biochem. Biophys., 2015, 464, 275.

18 F. Darain, P. Yager, K. L. Gan and S. C. Tjin, Biosens. Bioelectron., 2009, 24, 1744-1750.

19 Y. Shen, S. Liu, J. Yang, L. Wang, X. Tan and Y. He, Sens. Actuators, B, 2014, 199, 389-397.

20 J. F. Fong, S. F. Chin and S. M. Ng, Biosens. Bioelectron., 2016, 85, 844-852.

21 H. Miao, L. Wang, Y. Zhuo, Z. Zhou and X. Yang, Biosens. Bioelectron., 2016, 86, 83-89.

22 J. Jun, J. S. Lee, H. S. Dong and J. Jang, ACS Appl. Mater. Interfaces, 2014, 6, 13859-13865.

23 K. Sefah, J. A. Phillips, X. Xiong, L. Meng, S. D. Van, H. Chen, J. Martin and W. Tan, Analyst, 2009, 134, 1765-1775.

24 Q. Wang, W. Liu, Y. Xing, X. Yang, K. Wang, R. Jiang, P. Wang and Q. Zhao, Anal. Chem., 2014, 86, 6572.

25 M. Blind and M. Blank, Mol. Ther.-Nucleic Acids, 2015, 4, e223.

26 Z. Ghasemi, R. Dinarvand, F. Mottaghitalab, M. Esfandyarimanesh, E. Sayari and F. Atyabi, Carbohydr. Polym., 2015, 121, 190-198.

27 M. Zhang, S. M. Guo, Y. R. Li, P. Zuo and B. C. Ye, Chem. Commun., 2012, 48, 5488-5490.

28 X. Cui, L. Zhu, J. Wu, Y. Hou, P. Wang, Z. Wang and M. Yang, Biosens. Bioelectron., 2015, 63, 506-512.

29 C. Yu, X. Li, F. Zeng, F. Zheng and S. Wu, Chem. Commun., 2012, 49, 403-405.

30 Q. Y. Cai, J. Li, J. Ge, L. Zhang, Y. L. Hu, Z. H. Li and L. B. Qu, Biosens. Bioelectron., 2015, 72, 31-36.

31 J. Kudr, L. Richtera, K. Xhaxhiu, D. Hynek, Z. Heger, O. Zitka and V. Adam, Biosens. Bioelectron., 2017, 92, 133-139.

32 J. Jana, T. Aditya, M. Ganguly and T. Pal, Sens. Actuators, B, 2017, 188, 551-560.

33 P. Zhang, H. Liu, S. Ma, S. Men, Q. Li, X. Yang, H. Wang and A. Zhang, Biosens. Bioelectron., 2016, 80, 538-542.

34 C. H. Guo, R. Wang, J. Jing, F. Ji, G. Z. Feng, L. Nian Bing and L. H. Qun, Biosens. Bioelectron., 2016, 77, 40-45.

35 J. Sun, W. Jiang, J. Zhu, W. Li and L. Wang, Biosens. Bioelectron., 2015, 70, 15-20.

36 C. Y. Lee, K. S. Park, Y. K. Jung and H. G. Park, Biosens. Bioelectron., 2017, 93, 293-297.

37 E. Nevo, K. Kishi and A. Beiles, Biochem. Genet., 1990, 28, 561-570.

38 V. F. Martínez, E. Balada, J. Ordi-Ros and M. Vilardell-Tarres, Autoimmun. Rev., 2008, 7, 359-363.

39 X. Zhang, X. Fu, Y. Zhang, Y. Zhu and J. Yang, Catal. Lett., 2016, 146, 1-6.

40 M. Hai, M. Zheng, L. Yang, P. Keming, Y. Hang, W. Fang and K. Zhenhui, Dalton Trans., 2012, 41, 9526-9531.

41 B. Feng, L. Guo, L. Wang, F. Li, J. Lu, J. Gao, C. Fan and Q. Huang, Anal. Chem., 2013, 85, 7732-7737.

42 Z. Min, Y. Bin-Cheng, W. Xian-Fei and Y. Bang-Ce, Chem. Commun., 2011, 47, 2399-2401. 